\title{
Evaluation of Combined Excavation Waste and Reclaimed Asphalt Pavement Aggregates for Use in Road Bases and Sub-bases
}

\section{Ramzi Taha ${ }^{1 *}$, Okan Sirin ${ }^{1}$ and Husam Sadek ${ }^{1,2}$}

${ }^{1}$ Department of Civil \& Architectural Engineering, Qatar University, Doha, Qatar

${ }^{2}$ Centre for Engineering Sustainability, University of Liverpool, Liverpool, UK

\begin{abstract}
More than 15 million tons of aggregates are imported each year to Qatar from neighbouring countries. Large quantities of waste materials (around 20 million tons/year) from excavation waste, demolition rubble and reclaimed asphalt pavement (RAP) are being generated. The main objective of this paper is to present the results on the use of combined excavation waste (EW) and RAP aggregates in the construction of road bases and sub-bases. Physical and chemical properties were determined. Different combinations of both materials were subjected to compaction and California Bearing Ratio (CBR) testing in accordance with Qatar Construction Specifications. Results indicated that, for the materials tested, it is not feasible to use excavation waste, RAP aggregates or a combination of the two materials in road bases and sub-bases. The materials failed to meet some Qatari standards such as Los Angeles abrasion, liquid limit, plasticity index and CBR specified for road construction.
\end{abstract}

Keywords: Excavation; Waste; Reclaimed; Asphalt; Road; Recycling

\section{Introduction}

Waste materials are commonly used in construction projects in order to save natural resources for future generations. Road construction is one of the main users of these natural resources. Utilizing these materials in unbound base/sub-base construction will provide sustainable development in a country by saving virgin materials, conserving energy and diverting materials from landfills [1,2]. Recycled materials used in asphalt pavements and unbound base/sub-base applications mainly come from construction and demolition wastes (CDW), solid wastes (SW) and by-products from industrial processes. Most commonly used ones include coarse and fine aggregates, tiles, bricks obtained from CDW and excavation wastes (EW), reclaimed asphalt pavement (RAP), incinerator bottom ash (IBA), crumb rubber, fly ash, plastics and glass [3]. Demolition waste is the material that results from the destruction of a structure, specifically reinforced concrete structures, or generally from a structure/object that contains sand and cement.

In some countries where aggregate and sand resources are limited, these wastes are usually recycled and harvested for other construction purposes. Another source of wastes that could be recycled for construction use is the materials that are generated from ground excavation. These materials are formed due to excavation work during the construction phase of a structure, underground infrastructure and metro stations. The material usually consists of natural soil of the excavated location; it also might contain other materials like wood and organic material.

Reclaimed asphalt pavement (RAP) is another waste material generated when asphalt pavements are removed for reconstruction and resurfacing. They are commonly used in hot-mix asphalt courses and unbound base/sub-base applications as well Kallas [4], Decker and Young [5].

Economic, industrial and population growth in Qatar will generate increasing amounts of waste materials that must be disposed of. As the volume of wastes continues to grow, the approval and availability of facilities for waste processing and proper disposal will become more difficult to obtain. In addition, Qatar suffers from the availability of quality aggregates and materials that could be utilized in road, parking and building construction. Most of the aggregate used in the country is imported from the United Arab Emirates, Oman and Saudi Arabia. It is estimated that approximately 15 million tons of aggregate are imported every year. At the same time, Qatar generates large quantities of building and construction wastes, including milled asphalt pavements and demolition rubble (close to 20 million tons a year), which could be recycled in road construction.

\section{Research Objective and Scope of Work}

The main objective of this research project was to investigate the potential for constructing road bases and sub-bases from waste materials generated in the State of Qatar. To meet this objective, physical and chemical properties of excavation waste (EW) and reclaimed asphalt pavement (RAP) aggregates were determined. Then combinations of EW and RAP were subjected to compaction and California Bearing Ratio (CBR) tests. Results were compared with Qatar Construction Specifications [1] to establish the viability of using such materials in the base and sub-base structure.

\section{Materials}

Three waste materials, namely Excavation Waste-1 (EW1), Excavation Waste-2 (EW2) and RAP were collected from several locations around Doha (Capital of Qatar). RAP materials consist of limestone aggregate and aged Pen 60/70 bitumen. No pre-treatment was done to the materials of this study. A total of 25 buckets for each type of waste material were sampled from stockpiles and brought to our construction materials laboratories for physical, chemical, and mechanical testing. The following tests were conducted on the three waste materials in accordance with Qatar Construction Specifications (QCS-2010).

- $\quad$ Sieve analysis (ASTM C 136)

- Density, bulk specific gravity and absorption of coarse and fine aggregates (ASTM C 127 and ASTM C 128)

*Corresponding author: Ramzi Taha, Department of Civil and Architectural Engineering, Qatar University, P.O. Box 2713, Doha, Qatar, Tel: + 9744403 4118; E-mail: ramzitaha@qu.edu.qa

Received January 29, 2014; Accepted March 27, 2014; Published April 04, 2014

Citation: Taha R, Sirin O, Sadek H (2014) Evaluation of Combined Excavation Waste and Reclaimed Asphalt Pavement Aggregates for Use in Road Bases and Sub-bases. J Civil Environ Eng 4: 141. doi:10.4172/2165-784X.1000141

Copyright: ( 2014 Taha R, et al. This is an open-access article distributed under the terms of the Creative Commons Attribution License, which permits unrestricted use, distribution, and reproduction in any medium, provided the original author and source are credited. 
- $\quad$ Los Angeles abrasion test (ASTM C 131)

- $\quad$ Sand equivalency test (ASTM D 2419)

- $\quad$ Liquid limit and plasticity index tests (BS 1377) [6]

- Chemical leachate analysis

- $\quad$ Compaction (ASTM D698)

- California Bearing Ratio (CBR) test (ASTM D 698 and ASTM D 1883)

\begin{tabular}{|c|c|c|c|c|}
\hline Property & Specific gravity & $\begin{array}{c}\text { Absorption } \\
(\%)\end{array}$ & $\begin{array}{c}\text { Bulk density } \\
\left(\mathrm{kg} / \mathrm{m}^{3}\right)\end{array}$ & $\begin{array}{c}\text { Los Angeles } \\
\text { abrasion }(\%)\end{array}$ \\
\hline EW1 & 2.22 & 8.74 & 1,501 & 50.1 \\
\hline EW2 & 2.47 & 6.57 & 1,665 & 60.3 \\
\hline RAP & 2.41 & 2.35 & 1,692 & 43.1 \\
\hline QCS-2010 & N/A & N/A & N/A & $\leq 40$ \\
\hline
\end{tabular}

N/A: Typical values are not mentioned in QCS

Table 1: Physical properties of coarse aggregates.

\begin{tabular}{|c|c|c|c|c|c|c|}
\hline Property & $\begin{array}{c}\text { Specific } \\
\text { gravity }\end{array}$ & $\begin{array}{c}\text { Absorption } \\
(\%)\end{array}$ & $\begin{array}{c}\text { Bulk density } \\
\left(\mathrm{kg} / \mathrm{m}^{3}\right)\end{array}$ & $\begin{array}{c}\text { Sand } \\
\text { equivalent (\%) }\end{array}$ & $\begin{array}{c}\text { Liquid } \\
\text { limit (\%) }\end{array}$ & $\begin{array}{c}\text { Plasticity } \\
\text { index (\%) }\end{array}$ \\
\hline EW1 & 2.15 & 11.8 & 1,570 & 23 & 39.2 & 12 \\
\hline EW2 & 2.28 & 12.4 & 1,225 & 29 & 48 & 20.1 \\
\hline RAP & 2.01 & 1.2 & 1,487 & 96 & NP & NP \\
\hline $\begin{array}{c}\text { QCS } \\
2010\end{array}$ & N/A & N/A & N/A & $\geq 25$ & $\leq 25$ & $\leq 6$ \\
\hline
\end{tabular}

N/A: Typical values are not mentioned in QCS NP: non-plastic

Table 2: Physical properties of fine aggregates.

\begin{tabular}{|c|c|c|c|c|c|c|}
\hline \multirow{2}{*}{$\begin{array}{c}\text { Sieve size } \\
(\mathbf{m m})\end{array}$} & \multicolumn{7}{|c|}{ PW1 } & EW2 & RAP & $\begin{array}{c}\text { Class A } \\
\text { (QCS-2010) }\end{array}$ & $\begin{array}{c}\text { Class B } \\
\text { (QCS-2010) }\end{array}$ & $\begin{array}{c}\text { Class C } \\
\text { (QCS- 2010) }\end{array}$ \\
\hline $\mathbf{6 3}$ & 100 & 100 & 100 & 100 & - & - \\
\hline $\mathbf{5 0}$ & 100 & 100 & 100 & $90-100$ & 100 & - \\
\hline $\mathbf{3 7 . 5}$ & 93.9 & 85.2 & 100 & $60-90$ & $70-100$ & - \\
\hline $\mathbf{2 5}$ & 78.7 & 77.8 & 98 & $42-77$ & $55-85$ & 100 \\
\hline $\mathbf{2 0}$ & 69.1 & 70.5 & 95 & $35-70$ & $50-80$ & $90-100$ \\
\hline $\mathbf{1 0}$ & 52.4 & 53.0 & 65 & $25-60$ & $40-70$ & $50-85$ \\
\hline $\mathbf{5}$ & 41.2 & 40.2 & 22 & $15-40$ & $30-60$ & $35-65$ \\
\hline $\mathbf{2 . 3 6}$ & 33.6 & 32.5 & 7 & $10-26$ & $20-50$ & $25-50$ \\
\hline $\mathbf{0 . 4 2 5}$ & 19.8 & 19.0 & 0.6 & $5-15$ & $10-30$ & $15-30$ \\
\hline $\mathbf{0 . 0 7 5}$ & 5.5 & 5.3 & 0.1 & $2-9$ & $5-15$ & $5-15$ \\
\hline
\end{tabular}

Table 3: Sieve analysis results and gradation limits in QCS.

\section{Test Results and Discussion}

\section{Physical tests}

Physical properties of each of the three materials were determined in the laboratory. A summary of test results for coarse and fine aggregates are presented in Tables 1 and 2, respectively. Table 1 indicates that all three materials did not meet the maximum $40 \%$ LA Abrasion criteria in QCS. However, Los Angeles abrasion value for the RAP material (43.1\%) was only slightly higher than that of the QCS requirement.

Table 2 indicates that liquid limit and plasticity index results obtained for EW1 and EW2 didn't meet QCS standards. However, the sand equivalent for EW2 and RAP materials were satisfactory. The sand equivalent value for EW1 was slightly less than that of the QCS requirements of a minimum of $25 \%$.

In order to determine the grain size distribution of materials collected from the field, sample sizes were reduced using a splitter to collect enough material to run the sieve analysis test according to ASTM C 136 [7]. Figure 1 shows the sieve analysis results for EW1 material along with the upper and lower limits for Class A base course given in QCS. Figure 1 indicates that \% passing amount for some sieve sizes are outside the upper and lower limits and thus do not meet the specification requirement.

All sieve analysis results for the three materials and \% passing requirements for two types of bases (Classes A and B) and one type of sub-base (C) given in QCS are presented in Table 3. The results indicates that EW1 and EW2 materials can meet the requirements for a Class B type base course, but not those of Class A base and Class C sub-base. The materials failed to meet the percent passing requirements for many of the gradation sizes. Also, RAP material did not meet the \% passing requirement for any type of unbound base and sub-base courses given in QCS.

\section{Chemical tests}

Table 4 shows the concentrations of chemical constituents present in the leachate of the two excavation waste sources (EW1 and EW2) and the reclaimed asphalt pavement (RAP) aggregate. The QCS doesn't have standard for the concentrations of chemical constituents were results are reported in part per billion and they are extremely low to present. Such materials are safe to use and no water pollution should be anticipated from their use in road construction.

\section{Mechanical tests}

Mechanical tests in this project focused on two main tests, the

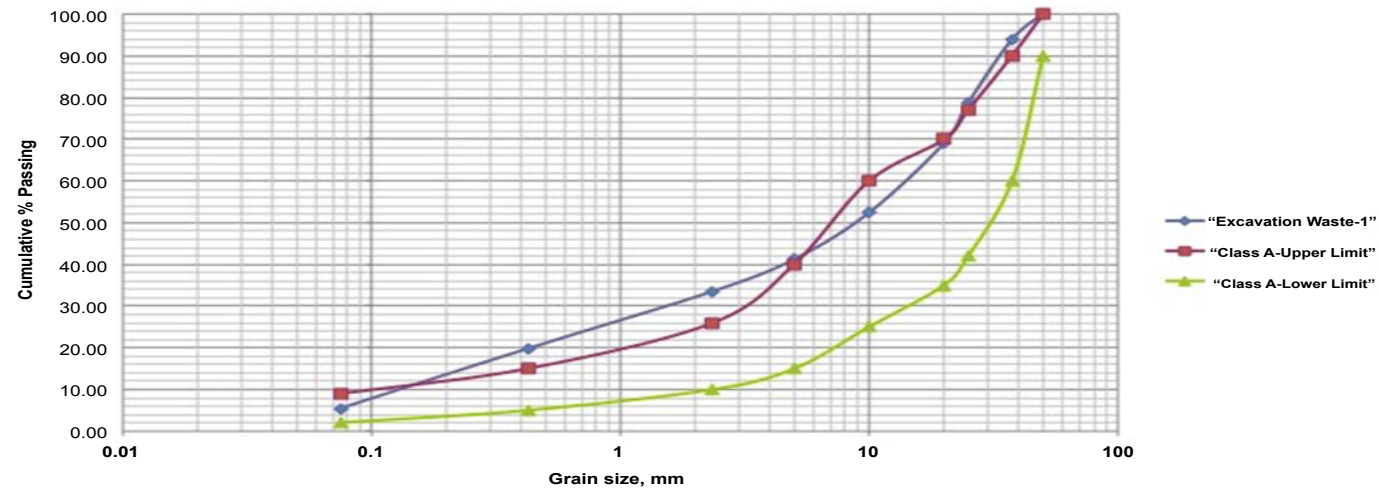

Figure 1: Sieve analysis results for excavation waste from site 1 (EW1). 
Citation: Taha R, Sirin O, Sadek H (2014) Evaluation of Combined Excavation Waste and Reclaimed Asphalt Pavement Aggregates for Use in Road Bases and Sub-bases. J Civil Environ Eng 4: 141. doi:10.4172/2165-784X.1000141

Page 3 of 5

Standard Proctor Compaction test (ASTM D698) and the California Bearing Ratio (CBR) test (ASTM D1883). Table 5 presents the different $\mathrm{RAP} / \mathrm{EW}$ mixtures tested in our laboratories. The main reason for blending excavation waste and reclaimed asphalt pavement aggregate is to improve the shearing strength of excavation waste materials as they tend to be the weak part of the matrix.

\begin{tabular}{|c|c|c|c|}
\hline Element & EW1 & EW2 & RAP \\
\hline $\mathbf{M g}$ & 53,060 & 41,990 & 34,990 \\
\hline $\mathbf{A l}$ & 8,943 & 10,870 & 41,060 \\
\hline $\mathbf{C a}$ & 191,800 & 207,400 & 152,500 \\
\hline $\mathbf{T i}$ & 410.8 & 924.7 & 2,973 \\
\hline $\mathbf{V}$ & 20.92 & 29.46 & 164.4 \\
\hline $\mathbf{C r}$ & 30 & 53.41 & 197.2 \\
\hline $\mathbf{M n}$ & 111.3 & 158.8 & 629.3 \\
\hline $\mathbf{F e}$ & $4,243.5$ & $6,596.5$ & 34560 \\
\hline $\mathbf{C o}$ & $<0.02$ & 1.053 & 24.49 \\
\hline $\mathbf{N i}$ & 10.81 & 19.28 & 76.56 \\
\hline $\mathbf{C u}$ & 7.844 & 5.249 & 32.82 \\
\hline $\mathbf{Z n}$ & 4.055 & 9.677 & 28.56 \\
\hline $\mathbf{A s}$ & 2.54 & 3.891 & 1.353 \\
\hline $\mathbf{S e}$ & 0.462 & 0.5619 & 0.4113 \\
\hline $\mathbf{A g}$ & $<0.1$ & $<0.1$ & $<0.1$ \\
\hline $\mathbf{C d}$ & 0.0729 & 0.1149 & 0.1426 \\
\hline $\mathbf{B a}$ & 470.6 & 313.9 & 54.1 \\
\hline $\mathbf{H g}$ & 0.1276 & 0.115 & 0.09333 \\
\hline $\mathbf{P b}$ & 3.018 & 3.401 & 1.931 \\
\hline
\end{tabular}

Table 4: Concentrations of chemical constituents in leachate samples (ppb: part per billion).
Optimum moisture content: Laboratory compaction tests are usually used for determining the percent compaction and optimum water content needed for a dense mix. For this purpose, different amounts of water were added to sample mixes to determine the optimum moisture content (OMC) using the standard Proctor compaction test (ASTM D 698). Samples were compacted by 25 blows in 3 layers using a $24.5 \mathrm{~N}$ rammer dropped from a height of $305 \mathrm{~mm}$. Corrected moisture contents were determined after drying samples at an oven temperature of $110 \pm 5^{\circ} \mathrm{C}$ for 24 hours. A total of 21 sample mixes were prepared using different percentages of two materials (RAP+EW1 and $\mathrm{RAP}+\mathrm{EW} 2)$. The compaction curve for each mixture was established after a sufficient number of water contents were used.

Compaction graphs for all mixtures are shown in Figures 2-5. A summary of optimum moisture content (OMC) results are presented in

\begin{tabular}{|c|c|c|c|c|c|}
\hline Mix \# & RAP (\%) & EW1 (\%) & Mix \# & RAP (\%) & EW2 (\%) \\
\hline 1 & 0 & 100 & 12 & 0 & 100 \\
\hline 2 & 10 & 90 & 13 & 10 & 90 \\
\hline 3 & 20 & 80 & 14 & 20 & 80 \\
\hline 4 & 30 & 70 & 15 & 30 & 70 \\
\hline 5 & 40 & 60 & 16 & 40 & 60 \\
\hline 6 & 50 & 50 & 17 & 50 & 50 \\
\hline 7 & 60 & 40 & 18 & 60 & 40 \\
\hline 8 & 70 & 30 & 19 & 70 & 30 \\
\hline 9 & 80 & 20 & 20 & 80 & 20 \\
\hline 10 & 90 & 10 & 21 & 90 & 10 \\
\hline 11 & 100 & 0 & & & \\
\hline
\end{tabular}

Table 5: Sample mixtures combinations' matrix.

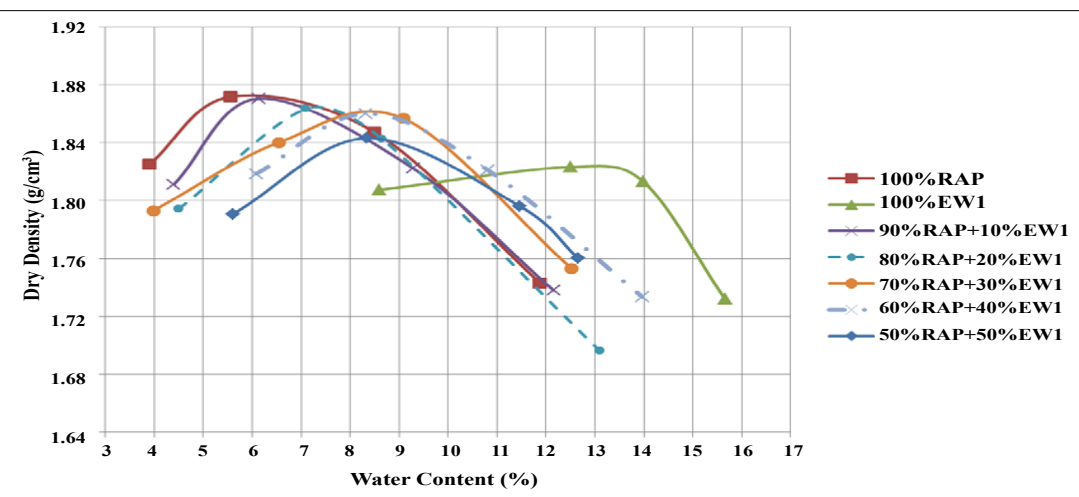

Figure 2: Compaction results for mix group 1.

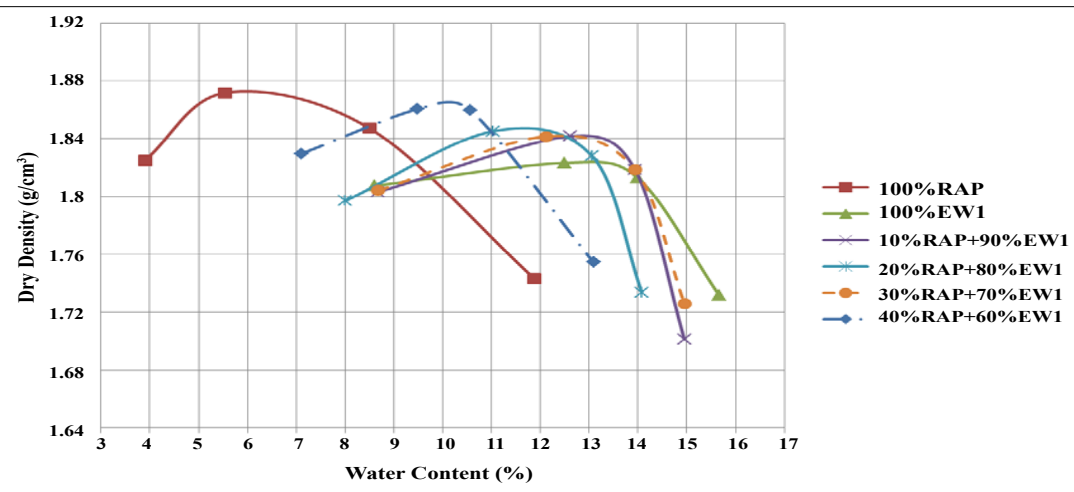

Figure 3: Compaction results for mix group 2. 

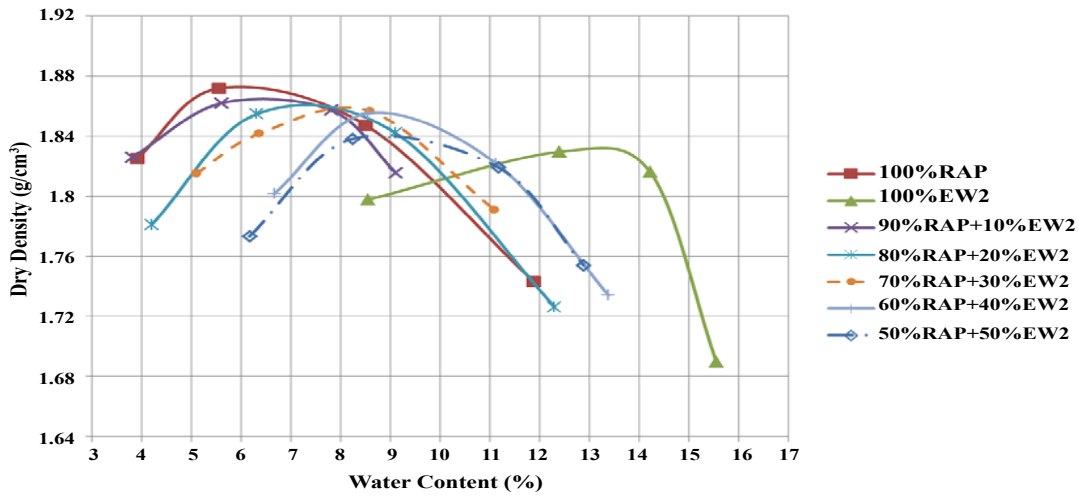

Figure 4: Compaction results for mix group 3

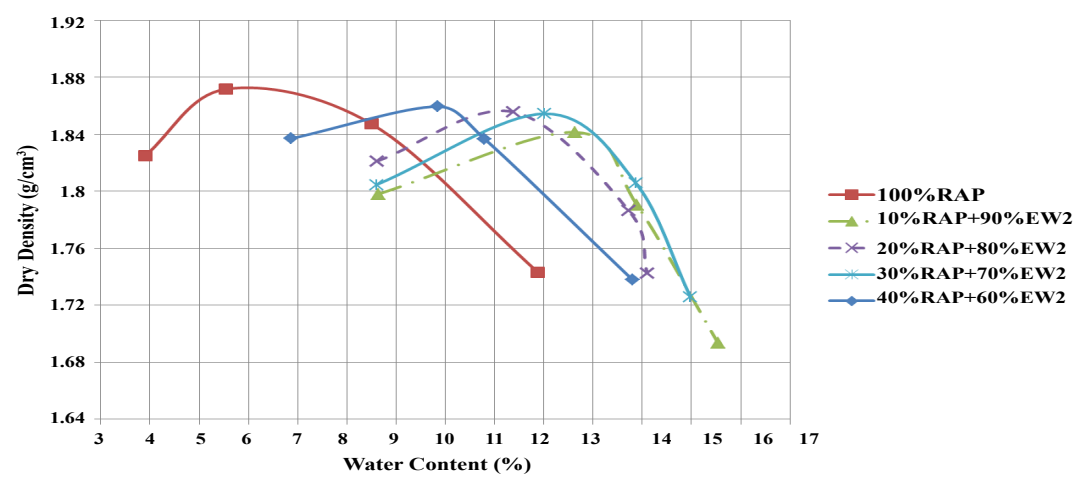

Figure 5: Compaction results for mix group 4.

\begin{tabular}{|c|c|c|c|c|c|c|c|}
\hline Mix \# & RAP (\%) & EW1 (\%) & OMC (\%) & Mix \# & RAP (\%) & EW2 (\%) & OMC (\%) \\
\hline 1 & 0 & 100 & 13.9 & 12 & 0 & 100 & 13.7 \\
\hline 2 & 10 & 90 & 13.6 & 13 & 10 & 90 & 13.4 \\
\hline 3 & 20 & 80 & 12.5 & 14 & 20 & 80 & 12.9 \\
\hline 4 & 30 & 70 & 12.7 & 15 & 30 & 70 & 13.1 \\
\hline 5 & 40 & 60 & 10.1 & 16 & 40 & 60 & 10.1 \\
\hline 6 & 50 & 50 & 9.6 & 17 & 50 & 50 & 9.8 \\
\hline 7 & 60 & 40 & 9.1 & 18 & 60 & 40 & 9.1 \\
\hline 8 & 70 & 30 & 9.0 & 19 & 70 & 30 & 8.3 \\
\hline 9 & 80 & 20 & 7.9 & 20 & 80 & 20 & 7.9 \\
\hline 10 & 90 & 10 & 6.4 & 21 & 90 & 10 & 6.8 \\
\hline 11 & 100 & 0 & 5.8 & & & & \\
\hline
\end{tabular}

Table 6: Summary of compaction results.

Table 6. The results indicate that as the percentage of RAP is increased in the mix there is a decrease in the OMC and an increase in dry density. This can be attributed to the better shear strength interlocking between the RAP particles and the fines from the EW.

California bearing ratio (CBR) results: Samples were compacted at the OMC in accordance with ASTM D 698 (standard Proctor compaction test). Then, compacted samples were soaked in water for 96 hours prior to conducting the California Bearing Ratio (CBR) test (ASTM D 1883). No swelling was observed in the soaked samples.

Load versus penetration curves for all mixtures were obtained for all mixtures. Figure 6 shows a typical load versus penetration graph for Mix Group 1. A summary of CBR results obtained at penetrations of 2.5 and $5 \mathrm{~mm}$ are presented in Table 7. A maximum CBR of $19.3 \%$ was obtained for $100 \%$ RAP. $100 \%$ excavation waste from Sites 1 and 2 generated low CBR values of 6.1 and $7.1 \%$, respectively. As the percentage of RAP was increased in the mixture, there was an increase in the CBR value. However, none of the CBR values obtained for all the mixtures met the minimum QCS-2010 requirements of 60 and $80 \%$ for road sub-bases and bases, respectively

\section{Conclusion and Recommendations}

\section{Conclusions}

Two excavation waste and one reclaimed asphalt pavement (RAP) aggregate materials collected from different locations in Qatar were investigated for possible use in road base and sub-bases in the State of Qatar. Physical, chemical and mechanical tests were conducted on a 
Citation: Taha R, Sirin O, Sadek H (2014) Evaluation of Combined Excavation Waste and Reclaimed Asphalt Pavement Aggregates for Use in Road Bases and Sub-bases. J Civil Environ Eng 4: 141. doi:10.4172/2165-784X.1000141

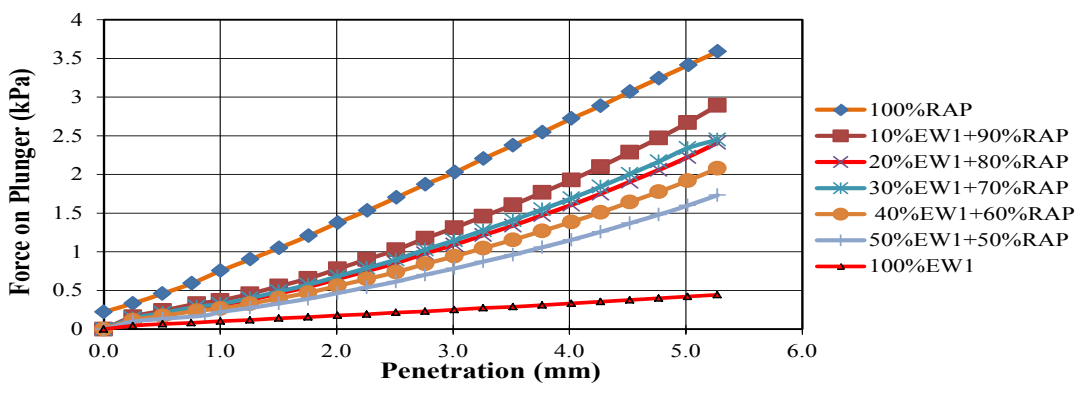

Figure 6: Load versus penetration for mix group 1.

\begin{tabular}{|c|c|c|c|c|c|c|c|c|c|c|c|}
\hline Sample & $\begin{array}{l}\text { RAP } \\
(\%)\end{array}$ & $\begin{array}{l}\mathrm{EW1} \\
(\%)\end{array}$ & $\begin{array}{c}\text { OMC } \\
(\%)\end{array}$ & $\begin{array}{c}\text { CBR (\%) @ } \\
2.5 \mathrm{~mm}\end{array}$ & $\begin{array}{c}\text { CBR (\%) @ } \\
5 \text { mm }\end{array}$ & Sample & $\begin{array}{l}\text { RAP } \\
(\%)\end{array}$ & EW2 (\%) & $\begin{array}{c}\text { OMC } \\
(\%)\end{array}$ & $\begin{array}{c}\text { CBR (\%) @ } \\
2.5 \mathrm{~mm}\end{array}$ & $\begin{array}{c}\text { CBR (\%) @ } \\
5 \text { mm }\end{array}$ \\
\hline 1 & 0 & 100 & 13.9 & 3.4 & 6.1 & 12 & 0 & 100 & 13.7 & 4.1 & 7.1 \\
\hline 2 & 10 & 90 & 13.6 & 3.8 & 7.2 & 13 & 10 & 90 & 13.4 & 4.3 & 7.4 \\
\hline 3 & 20 & 80 & 12.5 & 4.3 & 7.4 & 14 & 20 & 80 & 12.9 & 5.1 & 8.6 \\
\hline 4 & 30 & 70 & 12.7 & 4 & 7.6 & 15 & 30 & 70 & 13.1 & 6 & 10 \\
\hline 5 & 40 & 60 & 10.1 & 5.1 & 8.11 & 16 & 40 & 60 & 10.1 & 6.8 & 11.6 \\
\hline 6 & 50 & 50 & 9.6 & 6.3 & 9.7 & 17 & 50 & 50 & 9.8 & 7.1 & 13.6 \\
\hline 7 & 60 & 40 & 9.1 & 6.4 & 11.6 & 18 & 60 & 40 & 9.1 & 7.7 & 15.2 \\
\hline 8 & 70 & 30 & 9.0 & 8.2 & 15.4 & 19 & 70 & 30 & 8.3 & 8 & 16.4 \\
\hline 9 & 80 & 20 & 7.9 & 8.7 & 17.6 & 20 & 80 & 20 & 7.9 & 8.1 & 17.5 \\
\hline 10 & 90 & 10 & 6.4 & 9.6 & 18 & 21 & 90 & 10 & 6.8 & 9.8 & 18.1 \\
\hline 11 & 100 & 0 & 5.8 & 11 & 19.3 & & & & & & \\
\hline
\end{tabular}

Table 7: CBR and penetration results for mixes.

variety of mix proportions to determine their suitability according to QCS. Based on the data obtained from laboratory test, the following conclusions can be made:

- All three materials did not satisfy the Los Angeles Abrasion, liquid limit, plasticity index and CBR requirements for unbound materials specified in QCS.

- EW1, EW2 and RAP materials are not suitable in their current conditions for road bases and sub-bases construction in the State of Qatar.

\section{Recommendations}

Recommendations for future work should focus on:

- Stabilization of such materials with Portland cement to improve their strength.

- Blending with other virgin aggregates such as gabbro, gravel or limestone.

- Mixing with discarded aggregate generated in Qatar such as steel slag, aluminum dross and others.

\section{Acknowledgments}

This publication was made possible by a grant from the Qatar National Research Fund under its Undergraduate Research Experience Program (UREP), Award Number UREP 12-014-2-003. Its contents are solely the responsibility of the authors and do not necessarily represent the official views of the Qatar National Research Fund.

\section{References}

1. Qatar Construction Specifications-QCS (2010) Qatar.

2. El-Assaly A, Ellis R (2001) Evaluation of recycling waste materials and byproducts in highway construction. Int. Journal of Sustainable Development and World Ecology 8: 299-308.

3. Horvath A (2003) Life-Cycle Environmental and Economic Assessment of Using Recycled Materials for Asphalt Pavements. Technical Report, University of California-Berkeley.

4. Kallas BF (1984) Flexible pavement mixture design using reclaimed asphalt concrete. (FHWA/RD-84/088), Asphalt Institute, Lexington.

5. Decker DS, Young TJ (1996) Handling RAP in an HMA Facility. Proc. Canadian Technical Asphalt Association. Edmonton, Alberta, Canada.

6. BS 1377-1 (1990) Methods of test for soils for civil engineering purposes. General requirements and sample preparation. Standard Publication by BSI Group.

7. ASTM C136 - 06, Standard Test Method for Sieve Analysis of Fine and Coarse Aggregates. 